\title{
Markov Chain Models for Vegetation Dynamics
}

\author{
Heiko Balzter
}

8 Address of the author (also address for correspondence):

9 Heiko Balzter

10 Institute of Terrestrial Ecology

11 Monks Wood

12 Abbots Ripton

13 Huntingdon

14 Cambridgeshire

15 PE17 2LS

16 UK

$17 \quad$ Tel $+44(0) 1487773381$

$18 \quad$ Fax +44 (0) 1487773467

19 E-mail: Heiko.Balzter@ite.ac.uk

\section{Abstract}

25 A theoretical implementation of Markov chain models of vegetation dynamics is

26 presented. An overview of 22 applications of Markov chain models is presented, using

27 data from four sources examining different grassland communities with varying

28 sampling techniques, data types and vegetation parameters. For microdata, individual

29 transitions have been observed, and several statistical tests of model assumptions are 
30 performed. The goodness of fit of the model predictions is assessed both for micro- and

31 macrodata using the mean square error, Spearman's rank correlation coefficient and

32 Wilcoxon's signed-rank test. It is concluded that the performance of the model varies

33 between data sets, microdata generate a lower mean square error than aggregated

34 macrodata, and time steps of one year are preferable to three months. The rank order of

35 dominant species is found to be the most reliable prediction achievable with the models

36 proposed.

\section{Keywords}

40 Markov chains; Grassland; Prediction; Transition matrix models; Goodness of fit; Point41 quadrat method

\section{Introduction}

46 Predicting vegetation dynamics is no easy task, and some authors even doubt its

47 feasibility (Collins and Adams, 1983). A wide range of models have been developed for 48 application to vegetation data. These include deterministic and stochastic models for

49 time-series and spatio-temporal data. Markov chains are stochastic processes, and can be 50 parameterised by empirically estimating transition probabilities between discrete states

51 in the observed system. Their usefulness in forest communities in New England and

52 Wisconsin has been demonstrated as early as 1976 by Horn. In forests, transitions 
53 between saplings and mature trees are usually examined. Based on Horn's approach

54 other forest models were developed (Miles et al., 1985; Acevedo, 1981; Acevedo et al.,

55 1995). Post-fire succession in Quercus forests in France was modelled with Markov

56 chains by (Rego et al., 1993). Good predictions were also achieved by Runkle (1981).

57 Other authors, however, report a low validity of predictions in hardwood forests derived

58 from Markov chains (Barden, 1980; Binkley, 1980) and relate it to violations of the

59 underlying assumptions. The rapid development of new remote sensing techniques in

60 combination with improved GIS technology will potentially offer a wide range of

61 applications of Markov chains (see Hall et al., 1988).

63 Grassland is characterised by a variety of interacting factors, like inter- and intraspecific

64 competition, herbivory, weather and soil properties. Because of the large amount of

65 potentially important factors and their interactions influencing grassland dynamics, it is

66 very difficult to construct deterministic models. Approaches to the simulation of

67 grassland dynamics include the rule-based spatially-explicit model of two species by

68 Winkler and Klotz (1997), the use of artificial neural networks (Tan and Smeins, 1996),

69 and the gap model by Coffin and Lauenroth (1990). Despite the complexity of the

70 subject, stochastic models may empirically describe and predict changes in species

71 composition and abundance, saving costs and labour by avoiding measurements of a

72 large number of factors. Few authors have tried to apply Markov chains to grassland

73 (Cooke, 1981; Usher, 1987) and heathland (Hobbs and Legg, 1983; Lippe et al., 1985). 
75 The aim of this paper is to assess the applicability of Markov chain models to predict

76 vegetation changes using several different data sets, both from the scientific literature

77 and own observations. It is anticipated that the results and the insights in model

78 behaviour will also be useful for large-scale landscape ecosystem models by using

79 Markov chains as submodels.

80

81

\section{Markov chains}

83

84 The Russian mathematician Andrei Andreyevich Markov (1856-1922) developed the

85 theory of Markov chains in his paper 'Extension of the Limit Theorems of Probability

86 Theory to a Sum of Variables Connected in a Chain' (Markov, 1907). A Markov chain is

87 defined as a stochastic process fulfilling the Markov property (Eq.3) with a discrete state

88 space and a discrete or continuous parameter space. In this paper, the parameter space

89 represents time, and is considered to be discrete. Accordingly, a Markov chain

90 represents a system of elements making transitions from one state to another over time.

91 The order of the chain gives the number of time steps in the past influencing the

92 probability distribution of the present state, and can be greater than one.

93

94 The conditional probabilities $P\left(X_{t}=j \mid X_{s}=i\right)=p_{i j}(s, t)$ are called transition

95 probabilities of order $r=t-s$ from state $i$ to state $j$ for all indices $0 \leq s<t$, with

$961 \leq i, j \leq k$.

97 They are denoted as the transition matrix $P$. For $k$ states $P$ has the form 
99

$$
P=\left[\begin{array}{cccc}
p_{11} & p_{12} & \ldots & p_{1 k} \\
p_{21} & p_{22} & \ldots & p_{2 k} \\
\ldots & \ldots & \ldots & \ldots \\
\ldots & \ldots & \ldots \\
p_{k 1} & p_{k 2} & \ldots & p_{k k}
\end{array} \mid\right.
$$

101 At time 0 the initial distribution of states is $P\left(X_{0}=i\right)=p_{i}(0) \quad \forall i \in\{1, \ldots, k\}$

102 The state probabilities $p_{i}(t)$ at time $t$ are estimated from the relative frequencies of the $k$

103 states, resulting in the vector

104

105

$$
\underline{p}(t)=\left(p_{1}(t), p_{2}(t), \ldots, p_{k}(t)\right)
$$

106

107 Denoting the $v$-th observed state with $i_{v}$, a stochastic chain fulfilling Eq. 3 is a first-

108 order Markov chain:

109

$$
\begin{aligned}
& P\left(X_{t+1}=i_{v+1} \mid X_{t}=i_{v}, X_{t-1}=i_{v-1}, \ldots, X_{0}=i_{0}\right)=P\left(X_{t+1}=i_{v+1} \mid X_{t}=i_{v}\right) \\
& \forall v \geq 2, \forall i_{0}, i_{1}, \ldots, i_{v+1} \in\{1 \ldots k\}
\end{aligned}
$$

111

112 Predictions of future state probabilities can be calculated by solving the matrix equation:

113

114

$$
\underline{p}(t)=\underline{p}(t-1) \cdot P
$$

115

116 With increasing time steps, a Markov chain may approach a constant state probability

117 vector, which is called limiting distribution. 


$$
\underline{p}(\infty)=\lim _{t \rightarrow \infty} \underline{p}(t)=\lim _{t \rightarrow \infty} \underline{p}(0) \cdot P^{t}
$$

121 A state $i$ is called an 'absorbing state' if the state cannot be left again once it is entered,

122 i.e. $p_{i i}=1$. A Markov chain is time-homogeneous, if the transition probabilities are

123 constant over time (Binkley, 1980; Usher, 1981).

125 For several special cases where assumptions are violated, modifications of Markov chain 126 models have to be made. Transition probabilities are modelled as linearly dependent on 127 ecological factors by some authors (Usher, 1987; Baker, 1989). If the time intervals 128 between observations are not equal, specific estimation techniques are available 129 (Frydman, 1992; 1995a; 1995b).

\section{Material and methods}

\section{$134 \quad 3.1 \quad$ Model implementation}

136 Vegetation consists of several plant populations interacting with each other and site-

137 specific ecological factors (Odum, 1991). Changing ecological factors do not only 138 influence the performance of plant species but may in return be modified by the species 139 themselves, e.g. through nitrogen accumulation by Rhizobium bacteria. Each plant 140 species occupies a certain physical space, both above and below the ground. Imagining 
141 an abstract multidimensional space, bounded by available resources plant species again

142 occupy a certain space, the ecological niche (Pratt, 1995). Each dimension of this

143 resource space represents an ecological factor like $\mathrm{N}, \mathrm{P}, \mathrm{K}, \mathrm{pH}$, irradiation, land-use etc.

144 Limitations in resource availability delineate a subspace which includes the actually

145 consumable resources. Within this subspace one plant species has a better ability to

146 occupy a certain segment than other species, which in due course have to evade into

147 remaining segments or become locally extinguished. They may later colonise the site

148 again either by immigration or from the seed bank in the soil.

150 Here, for modelling vegetation dynamics with Markov chains plant species are regarded

151 as states of the chain. A transition from one state to another is equivalent to the

152 replacement of one species in a segment of the subspace of available resources by

153 another species. A species replacement occurs stochastically with a given probability.

154 The analysis of the transition probabilities alone may give insights into the abilities of

155 species to replace each other. However, predictions of future species proportions are

156 based on the following assumptions, if not stated otherwise:

157 - time-homogeneity

158 - spatial independence

159 - absence of colonisation by new species

160 - first-order Markov dependence

161

162 Statistical analyses were carried out using SPSS 6.1.3 and 7.5.2, and EXCEL 97. Graphs

163 were produced with CA-Cricket Graph III. If not stated otherwise $\alpha$ is assumed to be 5\% 
164 in hypothesis testing. Parameter estimation and calculation of predictions were

165 performed using the windows program Markov Chain Simulator 1.0 (MCS) which was

166 written in DELPHI 2.0 by the author. It encompasses a translated FORTRAN algorithm

167 published by Lee et al. (1970). MCS was verified using sample data from Lee et al.

168 (1970). The program is capable of reading macro- and microdata from ASCII files,

169 interactively testing some model assumptions and predicting and saving reports to an

170 output file in ASCII format. An SPSS 6.1.3 syntax file is automatically created, which

171 calculates Spearman's R, Wilcoxon's signed-rank test and the mean square error (mse)

172 and gives a histogram of the deviations of predictions from observations. MCS is

173 freeware and can be ordered from the author.

\subsection{Vegetation data}

177 To ensure the use of a wide variety of vegetation data from different sites, climatic and

178 soil conditions, three published data sets were taken from the literature and one from an

179 own experiment. To ensure sufficiently precise parameter estimation only a subset of

180 plant species is modelled. The criterion for species to be included is in having at least

$1815 \%$ percentage phytomass, percentage cover or proportion of specimen at one or more

182 observation times. For percentage phytomass and proportion of specimen, which add to

$183100 \%$, the other species are added up to a state 'others', while for percentage cover the

184 other species are excluded from analysis and percentage cover values are normalised. 


\section{Linden}

188 Five kilometres south of Giessen, Germany, is the experimental station Linden-

189 Leihgestern owned by the Justus-Liebig-University. The average yearly temperature is

$1909.1^{\circ} \mathrm{C}$ and the sum of precipitation per year $587 \mathrm{~mm}$. The site has a southern exposition

191 and is relatively dry. 6 m x 8 m plots were sown in April 1982 with $15 \mathrm{~g} / \mathrm{m}^{2}$ seeds. Seed

192 mixture A is a readily available mixture of grasses/herbs/legumes in proportions of

$19370 / 20 / 10$, containing seven annual herbs, while seed mixture $\mathrm{C}$ is a specially prepared

194 mixture of drought resistant species in proportions of 90/6.7/3.3 (Lüft, unpublished).

195 Plot LINDEN1 had 0 cuts per year, plot LINDEN2 had 1 cut, plot LINDEN3 had 2 cuts

196 and plot LINDEN4 had 4 cuts. Percentage phytomass was estimated each June. Seed

197 mixture B is not examined by Lüft (unpublished), but is known to behave similar to A.

199 Heiliges Meer

201 Runge (1985) studies the vegetation dynamics of sites that were allocated to the fen

202 nature reserve 'Heiliges Meer' near Hopsten in Northwest Germany in 1963 and 1976.

203 He uses permanent quadrats to observe changes in percentage cover. Runge points out

204 that the smallest quadrats are only sized $1 \mathrm{~m}^{2}$, but are nevertheless representative for the 205 surrounding vegetation.

206

207 Quadrat HEILIG1 is initially a wet ryegrass/white clover community (Lolio-

208 Cynosuretum lotetosum uliginosi) on peat. There are alder woods in $20 \mathrm{~m}$ 
209 distance. Runge (1985) describes a time series of 21 years with time steps of 3 years for

210 HEILIG1. Since 1963 no more cattle grazing is taking place on the site. In 1964 and

2111966 the site was covered with dead plant material which was penetrated only by a few

212 species like sorrel, Rumex acetosa. Over the years the vegetation makes the transition to

213 forest, dominated by alder (Alnus glutinosa), reaching a height of $1.50 \mathrm{~m}$ in $1967,8 \mathrm{~m}$ in

2141979 and $10 \mathrm{~m}$ in 1984. The increasing shade causes extinction of typical grassland

215 species while the shade-tolerant tufted hair grass, Deschampsia cespitosa, reaches high

216 percentage cover. Later a dense lawn of Yorkshire fog (Holcus lanatus) establishes

217 itself. Runge (1985) shows with another example that 17 years after cultivation has been

218 given up shrubs or trees are not necessarily present in this type of plant community.

220 Quadrat HEILIG2 is classified by Runge (1985) as a dry ryegrass/white clover

221 community (Lolio-cynosuretum typicum), which developed on a brownfield given

222 up in 1963 and consequently used for horse and sheep grazing. The soil is bleached sand

223 and poor in nutrients. The quadrat is sized $1 \mathrm{~m}^{2}$ and located in a fenced area which was

224 excluded from grazing between 1974 and 1980. Runge (1985) observes a transition to

225 the association Agrostietum tenuis.

226

227 The third quadrat HEILIG3 is sized $4 \mathrm{~m}^{2}$ and located on bleached sand rich in organic

228 material. This ryegrass/white clover community was subject to cattle grazing till 1965,

229 followed by horse and sheep grazing from 1965 till 1976, and excluded from grazing

230 from 1976 onwards. Since 1965 no fertilizer has been applied. Runge (1985) observes

231 diminishing proportions of character species of the grassland communities Molinio- 
232 Arrhenatheretea and increasing populations of Festuca rubra (creeping fescue),

233 Dactylis glomerata (cock's-foot) and H. lanatus. Runge reports on a thick layer of dead

234 plant material in 1982, causing decreasing percentage cover of $H$. lanatus and F. rubra.

236 Zagreb

238 Ilijanic et al. (1985) report on vegetation dynamics in three plots sized $9 \mathrm{~m}^{2}$ with

239 different soil moisture conditions in the Botanical Garden of Zagreb between 1964 and

240 1974. The mean daily temperature is $11.6^{\circ} \mathrm{C}$ and the sum of precipitation $925 \mathrm{~mm}$ per

241 year. The plots are initially free of vegetation, and succession is directed towards

242 grassland by two cuts per year. $30 \mathrm{~cm}$ wide strips separate the plots from each other.

243 There are hedges in the south and in the west, and the so-called 'systematic field' in the

244 north and east, which consists of many small plots where a great variety of species are

245 grown. Plot ZAGREB1 was irrigated with $576 \mathrm{~mm} / \mathrm{a}$ from March to November,

246 ZAGREB2 with $276 \mathrm{~mm} / \mathrm{a}$ and ZAGREB3 received no additional water. Numbers of

247 specimen of plant species were counted, the blades of grasses, the number of rooted

248 parts of creeping plants, and the rosettes of plants without stems above-ground (Iljanic et

249 al., 1985).

251 Giessen

252

253 Own data were sampled on a meadow in Giessen, Germany, by the point-quadrat

254 method (Goodall, 1952). The meadow is sized $616 \mathrm{~m}^{2}$ and regularly mown about ten 
255 times a year apart from an area in its centre. The point-quadrat frame holds three pins

256 one metre above the vegetation. Sampling is performed by lowering each pin through a

257 guide channel to the ground and then counting the number of contacts of the pin to each

258 plant species. The frame was moved along ten parallel transects, and samples were taken

259 at 12 frame positions on each transect. Methodological issues are described in Balzter et

260 al. (1995).

261

262 From the point-quadrat data, percentage phytomass is estimated by linear regression of

263 the parameter percentage of sward (PS) on species-specific dry phytomass proportions

$264(P M)$ obtained by cutting six $30 \mathrm{~cm}$ x $30 \mathrm{~cm}$ plots. Regression lines are fitted for herbs

265 and grasses separately, and three outliers are removed for herbs. The slopes of the lines

266 are used as calibration factors. For herbs the resulting equation is $P M=1.44 * P S$ with a

267 coefficient of determination $\mathrm{r}^{2}=0.72$ and for grasses $P M=0.77 * P S$ with $\mathrm{r}^{2}=0.98$. These

268 factors correct the bias caused by pin diameter, which causes overestimation of grasses

269 and underestimation of herbs due to the shapes of the leaves (Goodall, 1952).

271 In the analysis the three Poa species $P$. pratensis (smooth meadow-grass), $P$. trivialis

272 (rough meadow-grass) and $P$. апnua (annual meadow-grass) are aggregated to Poa spp.,

273 because of uncertainties in species determination in the field by the three observers when

274 the area was freshly mown. The mown and unmown area of the meadow showed

275 different vegetation types and are treated separately. Both seasonal and yearly

276 predictions are calculated from macro- and microdata. An overview of the eight different

277 model applications to the Giessen data and their abbreviations is given in Table 1. 


\subsection{Macrodata}

281 Macrodata are relative frequencies of states $p_{i}(t)$. Individual transition paths of a single

282 object are not recorded (Lee et al., 1970). In this study, normalised percentage cover,

283 proportion of specimen and percentage phytomass are used as state probabilities. Plant

284 species are defined as the states of the Markov chain, a definition which is related to the

285 concept of succession proposed by Pickett (1982). Estimation of the transition

286 probabilities is carried out with the maximum likelihood estimator $p_{*}$, which is equal to

287 the minimum $\chi^{2}$ and the least squares estimator:

$$
p_{*}=\left(X_{*}^{\prime} \Sigma_{*}^{-1} X_{*}\right)^{-1} X_{*}^{\prime} \Sigma_{*}^{-1} y_{*}
$$

291 Given observations at $T$ times and $k$ possible states, $p_{*}$ is a $(k(k-1))$ column vector, $X_{*}$ 292 is a $(T(k-1), k(k-1))$ block diagonal matrix with $k$-1 identical submatrices on the main

293 diagonal, $\Sigma_{*}^{-1}$ is the inverse of the covariance matrix with $T(k-1)$ rows and $T(k-1)$

294 columns, and $y_{*}$ is a $(T(k-1))$ column vector (Lee et al., 1970).

296 This estimator is subject to the constraints that $0 \leq p_{i j} \leq 1$. In practice, to hold the 297 constraints an iterative quadratic programming procedure (Lee et al., 1970) is used to 298 find the absolute or a local maximum of the likelihood function. If it does not provide a 299 single solution, a linear programming procedure and the minimum absolute deviations 300 estimator is used instead (Lee et al., 1970). 
302 Predictions are obtained by repeatedly multiplying the vectors of state probabilities with

303 the estimated transition matrix. The goodness of fit of the Markov chain is then assessed

304 by comparing predictions with observations on the frequencies of states at times $2, \ldots, T$

305 using Spearman's rank correlation coefficient, Wilcoxon's signed-rank test and the mean

306 square error.

307

$308 \quad 3.4 \quad$ Microdata

309

310 Microdata were only available for the Giessen test site. For microdata, transition paths of

311 single objects, in this case point-quadrats, over time are known. The mown area has 306,

312 the unmown area 54 objects. Each point-quadrat is characterised by a vector of the

313 numbers of contacts of each species to the pin. The state space is defined by clustering

314 the point-quadrats according to their species composition (SPSS 7.5.2, Quick Cluster);

315 three clusters form the state space of the mown and two of the unmown area. The

316 resulting transitions take place between plant communities, and correspond to the

317 concept of succession proposed by Knapp (1971). Predictions are calculated for cluster

318 frequencies, and the species-specific percentage phytomass is estimated by weighting

319 the predicted cluster frequencies with the mean phytomass per cluster. The maximum

320 likelihood estimator for microdata is obtained from the counted transition frequencies $n_{i j}$

321 from cluster $i$ to $j$ :

322 


$$
p_{i j}=\frac{n_{i j}}{\sum_{j} n_{i j}} \geq 0
$$

325 For microdata the likelihood ratio test from Anderson and Goodman (1957; cit. in Usher, 326 1987; see also Guttorp, 1995) for independence and identical distribution is applied. The 327 null hypothesis states independence, i.e. multinomial distribution of state probabilities, 328 and is accepted if the test statistic in Eq. 8 does not exceed the corresponding $\chi^{2}$ value 329 with $(k-1)^{2}$ degrees of freedom. Strictly speaking, the rejection of the null hypothesis is a 330 prerequisite for assuming a Markov chain.

331

$$
\chi_{i i d}^{2}=2 \sum_{i=1}^{k} \sum_{j=1}^{k} n_{i j} \ln \frac{p_{i j}}{p_{j}}, \quad \mathrm{df}=(k-1)^{2}
$$

334 with

$$
p_{j}=\frac{\sum_{i=1}^{k} n_{i j}}{\sum_{i=1}^{k} \sum_{j=1}^{k} n_{i j}}
$$

337 Time-homogeneity of the Markov chain is tested using another likelihood ratio test by

338 Anderson and Goodman (1957; cited in Usher, 1987). The test statistic in Eq. 9 is

339 obtained from the time-dependent transition probabilities $p_{i j}(t)$, and the time-independent

340 transition probabilities $p_{i j}$. If it exceeds the corresponding $\chi^{2}$ value, the null hypothesis

341 of time-homogeneity is rejected and tests for the order of the chain have to be

342 performed. 


$$
\chi_{\text {stat }}^{2}=2 \sum_{i=1}^{k} \sum_{j=1}^{k} \sum_{t=1}^{T} n_{i j}(t) \ln \frac{p_{i j}(t)}{p_{i j}}, \quad \quad \mathrm{df}=k(k-1)(T-1)
$$

346 Testing the order of the chain is possible for microdata using hierarchical $\chi^{2}$ tests

347 (Guttorp, 1995). Given $T$ observed times, one can iteratively test for all $r<T$-1 whether

348 the Markov chain is of $r$-th order. If the test statistic shown in Eq. 10 exceeds the

349 corresponding $\chi^{2}$ value, the null hypothesis of the chain being of $r$-th order is rejected.

350 Note that this procedure is problematic because the probability of falsely rejecting the

351 true order of the chain cannot be controlled (Guttorp, 1995).

$$
\chi_{\text {order }}^{2}=\sum_{a_{1}, \ldots, a_{T}} \frac{\left(n\left(a_{1}, \ldots, a_{T}\right)-n\left(a_{1}, \ldots, a_{T-1}\right) p\left(a_{1}, \ldots, a_{T-1} ; a_{T}\right)\right)^{2}}{n(a 1, \ldots, a T-1) p\left(a_{1}, \ldots, a_{T-1} ; a_{T}\right)}, \quad \mathrm{df}=(k-1) k^{r}\left(\mathrm{k}^{T-r-1}-1\right)
$$

355 where $p\left(a_{1}, \ldots, a_{T-1} ; a_{T}\right)=\frac{n\left(a_{T-r}, \ldots, a_{T-1}, a_{T}\right)}{n\left(a_{T-r}, \ldots, a_{T-1}\right)}$ is the estimator of the probability to change

356 to state $a_{T}$ after sequence $a_{T-r}, \ldots, a_{T-1}$;

$357 a_{i}$ is the $i$-th state from $\{1, \ldots, k\}$ and

$358 n\left(a_{1}, \ldots, a_{T-1}\right)$ is the number of observations of sequence $a_{1}, \ldots, a_{T-1}$.

360 According to the results of these likelihood ratio tests an appropriate Markov chain

361 model is selected. However, acceptance of the null hypothesis in the test for

362 independence and identical distribution is not regarded as sufficient evidence against a 
363 Markov chain, because it tests only $T$ and $T$-1. It rather indicates that the interpretation

364 has to be undertaken with greater care.

365

366 The results of testing the assumptions for the microdata of the Giessen test site are given

367 in Table 1. Time-inhomogeneity and higher ( $r$-th) order of the Markov chains are taken

368 into account by periodically applying different mean normalised transition matrices with

369 period $n_{p}=r$. These transition matrices are obtained by averaging and normalisation from

370 the $T-1$ time-dependent transition matrices.

371

372 The goodness of fit of the Markov chain is assessed in the same way as for macrodata.

373

374

3754 Results

376

377 The results presented in detail concentrate on a few examples that were selected to

378 illustrate the methodology. The same analyses were carried out for all described data

379 sets, and a comparison of the goodness of fit shows the variation of suitability of

380 Markov chain models across different examples of vegetation dynamics. Full details of

381 the applications of Markov models to all data sets are given in Balzter (1998).

382

\section{$383 \quad 4.1 \quad$ Predictions of vegetation dynamics}




\section{LINDEN2}

387 Plot LINDEN2 is mown once a year and was sown with seed mixture A. Figure 1 shows 388 the observed changes in vegetation composition and the corresponding predictions from 389 the Markov chain. Predictions are based on the percentage phytomass observations from 390 1982. The goodness of fit of the model can be assessed by comparing observations with 391 predictions from 1983 till 1986. Predicted changes in percentage phytomass are smaller 392 than observed, for instance the higher percentage phytomass of birdsfoot-trefoil, Lotus 393 spp., in 1984 and 1986 is smoothed by the model (Figure 1). The predictions from 1987 394 till 1991 show the expected development of the plant community beyond the observed 395 time frame. The predicted trend is that the community will be dominated by Achillea 396 millefolium (milfoil), Sanguisorba minor (salad burnet), Lotus spp. and Festuca 397 rubra/ovina. Beyond 1986 the Markov chain is approaching its limiting distribution and 398 the vegetation is predicted to be in equilibrium.

400 HEILIG3

402 HEILIG3 is used to illustrate Runge's (1985) data set. The decrease of H. lanatus and F. 403 rubra in 1982 reported by Runge (1985) is shown in Figure 2. Mainly A. millefolium and $404 R$. acetosa were able to penetrate this layer (Runge, 1985). Until 1984 no forest 405 established itself in the quadrat. Figure 2 shows that in 1980 the relative percentage 406 cover of F. rubra increases strongly. The observed dynamics in HEILIG3 do not show 407 any tendency towards a stable equilibrium. Accordingly, the Markov chain performs 
408 poorly, and its predictions deviate considerably from the observations. The smoothing

409 effect of the Markov chain (Figure 2) is likely to inhibit a good model fit to the highly

410 changing vegetation data. The observed increase in F. rubra in 1980, for example, is

411 also visible in the predictions, although it is predicted smaller than observed. The

412 dominance of A. millefolium in 1982 is not detected by the Markov chain. Unexpected

413 phenomena like the thick layer of dead plant material in 1982 which cause high rates of

414 change supposedly limit the usefulness of Markov chain models to vegetation dynamics.

415 Even if the Markov chain seems to be close to equilibrium of Agrostis capillaris

416 (common bent-grass) and F. rubra in 1989, the true limiting distribution approaches a

417 two-species mixture of creeping thistle, Cirsium arvense (64\%) and lesser stitchwort,

418 Stellaria graminea (36\%) after more than 300 time steps. Predictions on this time scale

419 are of course not interpretable given a data set over nine years.

\section{The mown area in Giessen}

423 The models with time steps of three months (MOMAC4 and MOMIC4) show poor 424 model fits and are not presented in detail. The models for the mown area in Giessen 425 using yearly time steps are shown together with the observed changes in percentage 426 phytomass in Figure 3. The observed changes include a decrease in Lolium perenne 427 (perennial rye-grass) and Trifolium repens (white clover), whereas the species

428 Ranunculus repens (creeping buttercup) and Glechoma hederacea (ground ivy) increase.

429 The dominant species Poa spp. reaches high percentage phytomass in 1996 but

430 decreases again thereafter. The macrodata model MOMACY predicts a further increase 
431 in G. hederacea and R. repens, and a continuous decline in Poa spp. (Figure 3). The

432 limiting distribution of MOMACY consists of $16 \%$ Poa grasses, $48 \%$ G. hederacea,

$43326 \%$ R. repens, 5\% T. repens and some species with low percentage phytomass. Despite

434 the fact that the predictions of MOMACY differ from MOMAC4, the rank order of the

435 four dominant species is identical in the first predicted year 1998. The predictions of

436 MOMICY are shown in Figure 3 (bottom). The plant community shows no predicted

437 trend, but is subject to periodic changes caused by the periodic use of three different

438 transition matrices. This periodicity could either be a real cyclic phenomenon of the

439 plant community or an artefact caused solely by a single event.

441 The four different models predict different vegetation dynamics. Stability (MOMAC4) is

442 contrasted by a slow increase in G. hederacea (MOMACY). Seasonal changes are

443 exhibited by MOMIC4, which does not show a trend over the years. MOMACY is

444 considered to be the most reliable model.

446 The unmown area in Giessen

448 Vegetation dynamics in the unmown area intermediately exhibits a rise of Poa spp.

449 which is followed by a subsequent decline (Figure 4 top). Medicago $x$ varia, a hybrid of

450 sickle medick (Medicago falcata) and alfalfa (Medicago sativa), makes up most of the

451 phytomass in 1993 but then rapidly loses weight in the plant community. The ruderal

452 species C. arvense and Urtica dioica (stinging nettle) increase their percentage

453 phytomass. In 1996 G. hederacea invades the unmown area, and reaches a high 
454 proportion of the phytomass in 1997 . Note that there is also a slow increase in the

455 proportion of the species category 'others' (Figure 4 top). The models using time steps of

456 three months are not discussed in detail, as their model fit is very poor. The macrodata

457 model UNMACY (Figure 4 centre) shows the smoothing effect of the Markov chain

458 compared to the observations. For instance, the observed sudden increase in $G$.

459 hederacea in 1997 is comparatively very small in the predictions, but lasts longer into

460 the future. In the model, G. hederacea eventually drives out all other species after

461 several hundred time steps and reaches $100 \%$ phytomass in the limiting distribution.

462 This is caused by the unitary transition probability from $G$. hederacea to itself. $G$.

463 hederacea is an absorbing state of the Markov chain. The predictions of the microdata

464 model UNMICY are presented in Figure 4 (bottom). They immediately reach a limiting

465 distribution with dominance of Poa spp. and M. $x$ varia.

466

$467 \quad 4.2$ Goodness of fit

468

469 The goodness of fit of the different Markov models for all used vegetation data sets is

470 used to assess their applicability for predicting vegetation dynamics of grassland

471 communities. The scatterplots of predicted versus observed values give a first

472 impression of the variability of goodness of fit (Figure 5). LINDEN2 shows a relatively

473 good model fit compared to HEILIG3. For the mown area of the Giessen test site

474 MOMACY and MOMICY show better model fits than MOMAC4 and MOMIC4, while

475 UNMACY is the only satisfying model for the unmown area (Figure 5). MOMAC4 and

476 UNMAC4 show inhomogeneity of the scatterplots. From the pairs of predictions and 
477 corresponding observations some statistics of the goodness of fit can be calculated.

478 Table 2 presents the mean square error (mse), Spearman's rank correlation coefficient

479 and the significance probability of Wilcoxon's signed-rank test. While the mse measures

480 the squared differences between predictions and observations, Spearman's R ranks the

481 values first and compares the rank orders. If $\mathrm{R}$ is close to one then the rank orders of

482 predicted and observed values correspond closely, and the model may at least be used to

483 predict a rank order of dominant plant species. Uncertainty of predicted values is

484 quantified by the mse. For instance, the $95 \%$ confidence interval calculated from twice

485 the root mean square error for a percentage phytomass of $30 \%$ would be approximately

$486 \mathrm{CI}_{95}=[10 \% ; 50 \%]$, assuming mse $=0.01$. Table 2 shows that a ranking of values $(\mathrm{R})$ gives

487 better results than metric predictions (mse). A graphical overview of the goodness of fit

488 of all models is given in Figure 6. LINDEN5, HEILIG3 and UNMAC4 exhibit

489 particularly poor model fits, while the predictions of LINDEN3, HEILIG2 and

490 MOMICY correspond well to the observations. The mse of HEILIG3 is almost tenfold

491 compared to HEILIG2.

492

493 The Wilcoxon test results in agreement of predictions with observations for all Markov

494 models except ZAGREB3, UNMAC4 and UNMIC4 (Table 2). R and mse of all models

495 are in comparable ranges. However, seasonal changes cause poor model fits, when time

496 steps of three months are used. The unmown area in Giessen shows generally poorer

497 model fits than the mown area, which is probably caused by the comparatively high rates

498 of change in the unmown plant community.

499 
500 For the Giessen test site a comparison of the goodness of fit of Markov models using

501 time steps of one year instead of three months and by using microdata instead of

502 macrodata was carried out. Except when comparing UNMICY to UNMACY, models

503 with microdata produce a smaller mse than models with macrodata (Table 3). A further

504 reduction of mse is generally achieved by using time steps of one year rather than three

505 months. Just UNMICY has a slightly greater mse than the corresponding model

506 UNMIC4, but as UNMIC4's predictions differ significantly from the observations

507 (Wilcoxon $P<0.05$ ), UNMICY is still preferable.

508

509

\section{Discussion}

511

512 Markov chain models have the advantage of aggregating very complex information in

513 the transition matrix, so that even ecosystems can be examined for which the underlying

514 processes are not fully understood. The applicability of Markov chain models to

515 vegetation dynamics of grassland communities is, however, limited by often occurring

516 unexpected disturbances or other events that change ecological factors drastically.

517 Events like an unusually cold winter could have the effect that the assumption of time-

518 homogeneous transition probabilities is violated. Such unexpected large shifts in species

519 composition were found in this study as well, confirming Binkley's (1980) findings.

520 Possible improvements could be the explicit modelling of changing weather using a

521 Hidden Markov model (Zucchini and Guttorp, 1991). This approach models transitions

522 between weather states as a Markov chain and uses transition matrices conditional on the 
523 particular weather state to predict the stochastic process of interest. If disturbing events

524 during data sampling are known, another option would be to estimate separate transition

525 matrices for time periods in which the assumption of time-homogeneity seems to be

526 better justified. If spatial autocorrelation is present in the data, a spatial model is more

527 appropriate. A generalisation of a Markov chain to a spatio-temporal Markov chain

528 (STMC), which is a type of cellular automaton model, is presented by Balzter et al.

529 (1998). One major drawback of this model is the rapidly increasing number of

530 parameters that need to be estimated, and this requires a very large spatial data set.

532 The mse found in the models examined in this paper is considered to be too high to

533 allow metric predictions of species composition in grassland. The metric variables are

534 valuable as input to the chain, but interpreting the predictions must be undertaken with

535 care. It is recommended to look at ranks of dominant species rather than predicting

536 species proportions in the community. The correlation of the ranks is measured by

537 Spearman's R. It is important to check whether the predicted ranks deviate significantly

538 from the observed ranks with Wilcoxon's signed-rank test, too. Although R is

539 satisfactory, Wilcoxon's P may still discover a poor model fit, if the majority of ranked

540 predictions is all higher or all lower than the observations (Figure 6). $\mathrm{R}$ is more robust

541 than Pearson's $r$, as the assumption of bivariate normal distribution is rarely true for

542 grassland communities, because usually only a few species have high proportions but

543 many have low proportions of the vegetation. This phenomenon was called 'law of

544 constants' in vegetation science by Raunkiaer (1934; cit. in Collins and Glenn, 1991). 
545 Cooke (1981) concludes that the validity of Markov chain predictions in grassland is

546 species-specific.

548 The predictions of the Markov chains are smoothed in comparison to the observations.

549 High rates of change in the plant community are particularly hard to model with Markov

550 chains because of this smoothing effect, and they cause a greater mse. Such high rates of

551 change are commonly observed in grassland communities (Dodd et al., 1995). Seasonal

552 variation causes the model to perform particularly poorly, when transitions are

553 influenced by the annual weather cycle (MOMAC4, MOMIC4, UNMAC4, UNMIC4).

555 Different data sets produce a different goodness of fit of the Markov chains. For 556 instance, the Linden plots with seed mixture A (LINDEN1 to LINDEN4) generally has a 557 lower mse and a greater $\mathrm{R}$ than seed mixture C (LINDEN5 to LINDEN8, Figure

558 6).There is no clear relationship between the goodness of fit and

559 - the modelled parameter (percentage phytomass, relative percentage cover, percentage

560 of specimen)

561 the sampling site (Linden, Heiliges Meer, Zagreb, Giessen)

562 the number of states in the model (two to 18, Table 2)

563 - the number of observed time steps (five to 15, Table 2).

565 The use of microdata instead of macrodata is likely to reduce the mse. Microdata are not 566 often available, though, and most vegetation records contain some kind of macrodata. 
567 Microdata also have the advantage that some statistical tests can be performed before

568 running the model, although these need careful interpretation of what is actually tested.

570 Regardless of the data type used, the first step is to define the state space of the chain. In

571 case of microdata obtained by the point-quadrat method, the multivariate observations

572 need to be classified before defining the state space. This approach models transitions

573 between vegetation types rather than between species. On the contrary, macrodata

574 models may be defined using single species as states. A decision has to be made, which

575 species to include in the model, because the number of parameters to be estimated

576 increases exponentially with the number of states. On the one hand, the more parameters

577 are necessary, the less precise the estimation becomes. On the other hand, omission of

578 important species may cause poor predictions. Some authors use only two states in their

579 vegetation Markov model (Usher, 1987), but others use more than ten (Miles et al.,

580 1985; Hobbs and Legg, 1983) or even 400 in a model of amino acid substitution (Gonnet

581 et al., 1994). To increase the precision of parameter estimation, the data set should

582 extend over a time period as long as possible.

583

584 In conclusion, Markov chains are a framework for estimated replacement rates (or 585 transition probabilities) between plant populations. They can contribute to the numerical 586 analysis and understanding of species replacements in a pathway of succession. The 587 mechanistic richness which is often observed in a succession (Pickett et al., 1987) is

588 summarised in the transition matrix. The existence of a limiting distribution of a Markov 589 chain implies a successional pathway with directional change and termination. 
590 Fluctuations in the plant community are smoothed by the Markov chain predictions, and

591 the remaining successional trend can be regarded as the expected dominance order of the

592 plant species. It has been shown that Markov chain models are sensitive to changes in

593 the frequency and regularity of disturbances, like cutting and grazing. Information about

594 land use practices are therefore essential for interpretation of the model predictions.

595 Despite the complex nature of grassland dynamics, it is possible to get good predictions

596 under certain circumstances with an appropriate model. The predictions achievable with

597 Markov chains are ranks of dominant species rather than metric variables.

598 There is still more potential for development of simple but sophisticated models of

599 grassland dynamics. But the information from Markov chain models surely is valuable

600 for conservation, landscape planning and ecology.

601

602

603 Acknowledgements

604

605 This project was funded by a grant from the Federal State of Hessen. I would like to

606 thank Prof Wolfgang Köhler and Paul Braun from Justus-Liebig-University (JLU)

607 Giessen, Germany, for their supportive supervision of my work. Paul Braun also took

608 part in vegetation sampling together with Marcus Hoffmann. My colleagues Gabriel

609 Schachtel, Elisabeth Schmidt and Antje Herrmann (JLU) provided very helpful

610 discussions. Angelika Hoffmann and Jörg von Prondzinski played an important role in

611 determination of plant species. Thanks to Peter North (ITE) for checking the manuscript. 612 


\section{References}

616 Acevedo, M.F., 1981. On Horn’s Markovian model of forest dynamics with particular

617 reference to tropical forests. Theor. Pop. Biol. 19: 230-250.

618 Acevedo, M.F., Urban, D.L. and Ablan, M., 1995. Transition and gap models in forest 619 dynamics. Ecol. Appl. 5: 1040-1055.

620 Baker, W., 1989. A review of models of landscape change. Landsc. Ecol. 2: 111-133.

621 Balzter, H., 1998. Modellierung der Vegetationsdynamik verschiedener

622 Pflanzengemeinschaften des Grünlandes mit Markov-Ketten. Boden und Landschaft 23,

623 Justus-Liebig-Universität, Giessen, 152 pp.

624 Balzter, H., Braun, P. and Köhler, W., 1995. Detection of spatial discontinuities in

625 vegetation data by a moving window algorithm. In: W. Gaul and D. Pfeifer (Editors),

626 From Data to Knowledge: Theoretical and Practical Aspects of Classification, Data

627 Analysis and Knowledge Organization, Springer, Berlin, pp. 243-252.

628 Balzter, H., Braun, P.W. and Köhler, W., 1998. Cellular automata models for vegetation 629 dynamics. Ecol. Model. 107: 113-125.

630 Barden, L.S., 1980. Tree replacements in a cove hardwood forest of the Southern 631 Appalachians. OIKOS 35: 16-19.

632 Binkley, C.S., 1980. Is succession in hardwood forests a stationary Markov process?

633 Forest Sci. 26: 566-570.

634 Coffin, D. P. and Lauenroth, W. K., 1990. A gap dynamics simulation-model of 635 succession in a semiarid grassland, Ecol. Model. 49: 229-266. 
636 Collins, S.L. and Adams, D.E., 1983. Succession in grasslands: thirty-two years of

637 change in a Central Oklahoma tallgrass prairie. Vegetatio 51: 181-190.

638 Collins, S.L. and Glenn, S.M., 1991. Importance of spatial and temporal dynamics in

639 species regional abundance and distribution. Ecology 72: 654-664.

640 Cooke, D., 1981. A Markov chain model of plant succession. In: R.W. Hiorns and D.

641 Cooke (Editors), The Mathematical Theory of the Dynamics of Biological Populations

642 II, Academic Press, London, pp. 231-247.

643 Dodd, M., Silvertown, J., McConway, K., Potts, J. and Crawley, M., 1995. Community

644 stability: a 60-year record of trends and outbreaks in the occurrence of species in the

645 park grass experiment. J. Ecol. 83: 277-285.

646 Frydman, H., 1992. A nonparametric estimation procedure for a periodically observed

647 three-state Markov process, with application to AIDS. Statistical Methodology 54: 853-

648866.

649 Frydman, H., 1995a. Nonparametric estimation of a Markov 'illness-death' process from

650 interval-censored observations, with application to diabetes survival data. Biometrika

$651 \quad 82: 773-789$.

652 Frydman, H., 1995b. Semiparametric estimation in a three-state duration-dependent

653 Markov model from interval-censored observations with application to AIDS data.

654 Biometrics 51: 502-511.

655 Gonnet, G.H., Cohen, M.A. and Benner, S.A., 1994. Analysis of amino acid substitution

656 during divergent evolution: the 400 by 400 depeptide substitution matrix. Biochem.

657 Biophys. Res. Commun. 199: 489-496. 
658 Goodall, D.W., 1952. Some considerations in the use of point quadrats for the analysis

659 of vegetation. Aust. J. Scient. Res. B 5: 1-41.

660 Guttorp, P., 1995. Stochastic Modeling of Scientific Data. Chapman and Hall, London, $661372 \mathrm{pp}$.

662 Hall, F.G., Strebel, D.E. and Sellers, P.J., 1988. Vegetation, atmosphere, climate and 663 remote sensing. Landsc. Ecol. 2: 3-22.

664 Heller, W.-D., Lindenberg, H., Nuske, M. and Schriever, K.-H., 1978. Stochastische 665 Systeme. De Gruyter, Berlin.

666 Hobbs, R.J. and Legg, C.J., 1983. Markov models and initial floristic composition in 667 heathland vegetation dynamics. Vegetatio 56: 31-43.

668 Horn, H.S., 1976. Succession. In: R.M. May (Editor), Theoretical Ecology. Principles 669 and Applications, Saunders, Philadelphia, pp. 187-204.

670 IIijanic, L., Topic, J. and Segulja, N., 1985. Meadow-succession experiment on the 671 permanent plots in botanical garden in Zagreb. In: K.-F. Schreiber (Editor), Sukzession 672 auf Grünlandbrachen, Schöningh, Paderborn, pp. 69-80.

673 Knapp, R., 1971. Einführung in die Pflanzensoziologie. Ulmer, Stuttgart.

674 Lee, T.C., Judge, G.G. and Zellner, A., 1970. Estimating the Parameters of the Markov

675 Probability Model from Aggregate Time Series Data. North-Holland Publishing

676 Company, Amsterdam, $261 \mathrm{pp}$.

677 Lippe, E., De Smidt, J.T. and Glenn-Lewin, D.C., 1985. Markov models and succession:

678 a test from a heathland in the Netherlands. J. Ecol. 73: 775-791. 
679 Markov, A., 1907. Extension of the limit theorems of probability theory to a sum of

680 variables connected in a chain. The Notes of the Imperial Academy of Sciences of St.

681 Petersburg, VIII Series, Physio-Mathematical College XXII, No. 9.

682 Miles, J., French, D.D., Zhen-Bang, X. and Ling-Zhi, C., 1985. Transition matrix

683 models of succession in a stand of mixed broadleaved-Pinus koraiensis forest in

684 Changbaishan, Kirin province, North-east China. J. Environ. Manage. 20: 357-375.

685 Odum, E.P., 1991. Prinzipien der Ökologie: Lebensräume, Stoffkreisläufe,

686 Wachstumsgrenzen. Spektrum der Wissenschaft, Heidelberg, 305 pp.

687 Pickett, S.T.A., 1982. Population pattern through twenty years of oldfield succession.

688 Vegetatio 49: 45-59.

689 Pickett, S.T.A., Collins, S.L. and Armesto, J.J., 1987. Models, mechanisms and

690 pathways of succession. Bot. Rev. 53: 335-371.

691 Pratt, C.R., 1995. Ecology. Springhouse, Springhouse, PA, 168 pp.

692 Rego, F., Pereira, J. and Trabaud, L., 1993. Modeling Community Dynamics of a

693 Quercus-Coccifera L garrigue in relation to fire using Markov chains. Ecol. Model. 66:

$694 \quad 251-260$.

695 Runge, F., 1985. 21-, 10- und 8-jährige Dauerquadratuntersuchungen in aufgelassenen

696 Grünländereien. In: K.-F. Schreiber (Editor): Sukzession auf Grünlandbrachen.

697 Schöningh, Paderborn, pp. 45-49.

698 Runkle, J.R., 1981. Gap regeneration in some old-growth forests of the eastern United

699 States. Ecology 62: 1041-1051.

700 Tan, S. S. and Smeins, F. E., 1996. Predicting grassland community changes with an

701 artificial neural network model. Ecol. Model. 84: 91-97. 
702 Usher, M.B., 1981. Modelling ecological succession, with particular reference to

703 Markovian models. Vegetatio 46: 11-18.

704 Usher, M.B., 1987. Modelling successional processes in ecosystems. In: A.J. Gray, M.J.

705 Crawley and P.J. Edwards (Editors), Colonization, Succession and Stability. Blackwell, 706 Oxford, pp. 31-56.

707 Winkler, E. and Klotz, S., 1997. Clonal plant species in a dry-grassland community: A

708 simulation study of long-term population dynamics. Ecol. Model. 96: 125-141.

709 Zucchini, W. and Guttorp, P., 1991. A hidden Markov model for space-time

710 precipitation. Water Resour. Res. 27: 1917-1923. 


\section{$\underline{\text { Tables }}$}

712 Table 1: Model applications to the meadow data from Giessen, with assumptions and results of 713 the statistical tests. Each application is abbreviated as indicated in capitals (e.g. MOMAC4 714 means mown, macrodata, 4 time steps per year). Note that for UNMICY the time-homogeneous, 715 mean transition matrix is used despite the test results given in the table, because one of the row 716 sums of the periodic matrices equals 0.

\begin{tabular}{|c|c|c|}
\hline $\begin{array}{l}\text { mown (MO) } \\
\text { unmown (UN) } \\
\text { area }\end{array}$ & $\begin{array}{c}\text { macrodata } \\
\text { (MAC) }\end{array}$ & $\begin{array}{l}\text { microdata } \\
(\mathrm{MIC})\end{array}$ \\
\hline $\begin{array}{l}4 \text { time steps per year } \\
03 / 1994-09 / 1997 \\
\text { (4) }\end{array}$ & $\begin{array}{l}\text { MOMAC4 } \\
\text { UNMAC4 } \\
\text { assumption of first-order, } \\
\text { time-homogeneous Markov chains }\end{array}$ & $\begin{array}{l}\text { MOMIC4 } \\
\text { independence of transitions, } \\
\text { fourth-order, } \\
\text { time-inhomogeneity } \\
\text { UNMIC4 } \\
\text { independence of transitions, } \\
\text { second-order, } \\
\text { time-inhomogeneity }\end{array}$ \\
\hline $\begin{array}{l}\text { yearly time steps } \\
06 / 1993-06 / 1997 \\
\text { (Y) }\end{array}$ & $\begin{array}{l}\text { MOMACY } \\
\text { UNMACY } \\
\text { assumption of first-order, } \\
\text { time-homogeneous Markov chains }\end{array}$ & $\begin{array}{l}\text { MOMICY } \\
\text { independence of transitions, } \\
\text { third-order, } \\
\text { time-inhomogeneity } \\
\text { UNMICY } \\
\text { independence of transitions, } \\
\text { third-order, } \\
\text { time-inhomogeneity }\end{array}$ \\
\hline
\end{tabular}


Table 2: Goodness of fit of the Markov models for all datasets. mse=mean square error, $\mathrm{R}=$ Spearman's rank correlation coefficient, $n=$ number of pairs for calculation of $\mathrm{R}$, $P=$ significance probability of the Wilcoxon signed-rank test (marked with ' $*$ ' if less than 0.05 ), pm $\%=$ percentage phytomass, $\mathrm{pc} \%=$ percentage cover, $\mathrm{ps} \%=$ percentage of specimen.

\begin{tabular}{|c|c|c|c|c|c|c|c|}
\hline dataset & parameter & $\begin{array}{c}\text { number of } \\
\text { states }\end{array}$ & $\begin{array}{c}\text { number of } \\
\text { observed time } \\
\text { steps }\end{array}$ & mse & $\bar{R}$ & $n$ & $P$ \\
\hline LINDEN1 & & 8 & 5 & 0.0084 & 0.92 & 32 & 0.350 \\
\hline LINDEN2 & & 8 & 5 & 0.0050 & 0.91 & 32 & 0.627 \\
\hline LINDEN3 & & 8 & 5 & 0.0027 & 0.97 & 32 & 0.360 \\
\hline LINDEN4 & $\mathrm{pm} \%$ & 10 & 5 & 0.0048 & 0.91 & 40 & 0.270 \\
\hline LINDE- $\bar{N} 5$ & & $9-$ & & $\overline{0} . \overline{0} 0 \overline{4}$ & $0 . \overline{7} \overline{5}$ & $\overline{3} \overline{6}$ & $0.300^{-}$ \\
\hline LINDEN6 & & 10 & 5 & 0.0133 & 0.69 & 40 & 0.119 \\
\hline LINDEN7 & & 8 & 5 & 0.0141 & 0.81 & 32 & 0.112 \\
\hline LINDEN8 & & 10 & 5 & 0.0030 & 0.90 & 40 & 0.192 \\
\hline HEILIG̈- & & $\overline{1} \overline{6}$ & 8 & $\overline{0} . \overline{0} \overline{3} \overline{4}$ & $\overline{0 . \overline{8}} \overline{7}$ & $\overline{119}$ & $0 . \overline{6} \overline{7}$ \\
\hline HEILIG2 & pc\% & 10 & 11 & 0.0018 & 0.91 & 110 & 0.859 \\
\hline HEILIG3 & & 9 & 9 & 0.0161 & 0.81 & 80 & 0.095 \\
\hline$\overline{Z A G R E B} \overline{1}$ & & $1 \overline{4}$ & $\overline{11}$ & $\overline{0} . \overline{0} \overline{4} \overline{2}$ & $0 . \overline{8} 8$ & $\overline{140}$ & $0 . \overline{38} \overline{4}$ \\
\hline ZAGREB2 & ps\% & 14 & 11 & 0.0068 & 0.70 & 140 & 0.677 \\
\hline ZAGREB3 & & 18 & 11 & 0.0049 & 0.85 & 180 & $0.004 *$ \\
\hline $\bar{M} \bar{O} \bar{M} \bar{A} \bar{C} \overline{4}$ & & 9 & $\overline{15}$ & $\overline{0} . \overline{0} \overline{5} \overline{6}$ & $1-$ & 126 & $\overline{0.8 \overline{4}} \overline{1}$ \\
\hline MOMACY & & 7 & 5 & 0.0043 & 0.88 & 28 & 0.554 \\
\hline MOMIC4 & & 3 & 15 & 0.0043 & 0.79 & 126 & 0.130 \\
\hline MOMICY & pm\% & 3 & 5 & 0.0020 & 0.87 & 28 & 0.909 \\
\hline UNMAC4 & & 12 & 15 & 0.0361 & - & 168 & $<0.001^{*}$ \\
\hline UNMACY & & 8 & 5 & 0.0065 & 0.86 & 32 & 0.340 \\
\hline UNMIC4 & & 2 & 15 & 0.0112 & 0.60 & 168 & $0.008^{*}$ \\
\hline UNMICY & & 2 & 5 & 0.0116 & 0.69 & 32 & 0.722 \\
\hline
\end{tabular}

Table 3: Reduction of mean square error (mse) caused by using time steps of one year instead of three months and by using microdata instead of macrodata. Ratios $<1$ actually reduce the mse and are shown in bold italic.

\begin{tabular}{lrr}
\hline land use & $\begin{array}{c}\text { time steps one year } \\
\text { instead of three months }\end{array}$ & microdata instead of macrodata \\
\hline mown & $\begin{array}{l}\text { microdata: } \mathbf{0 . 4 7} \\
\text { macrodata: } \mathbf{0 . 7 7}\end{array}$ & steps of one year: $\mathbf{0 . 4 7}$ \\
& steps of 3 months: $\mathbf{0 . 7 7}$ \\
\hline unmown & $\begin{array}{c}\text { microdata: } 1.04 \\
\text { macrodata: } \mathbf{0 . 1 8}\end{array}$ & steps of one year: $1 . \overline{79}$ \\
\end{tabular}



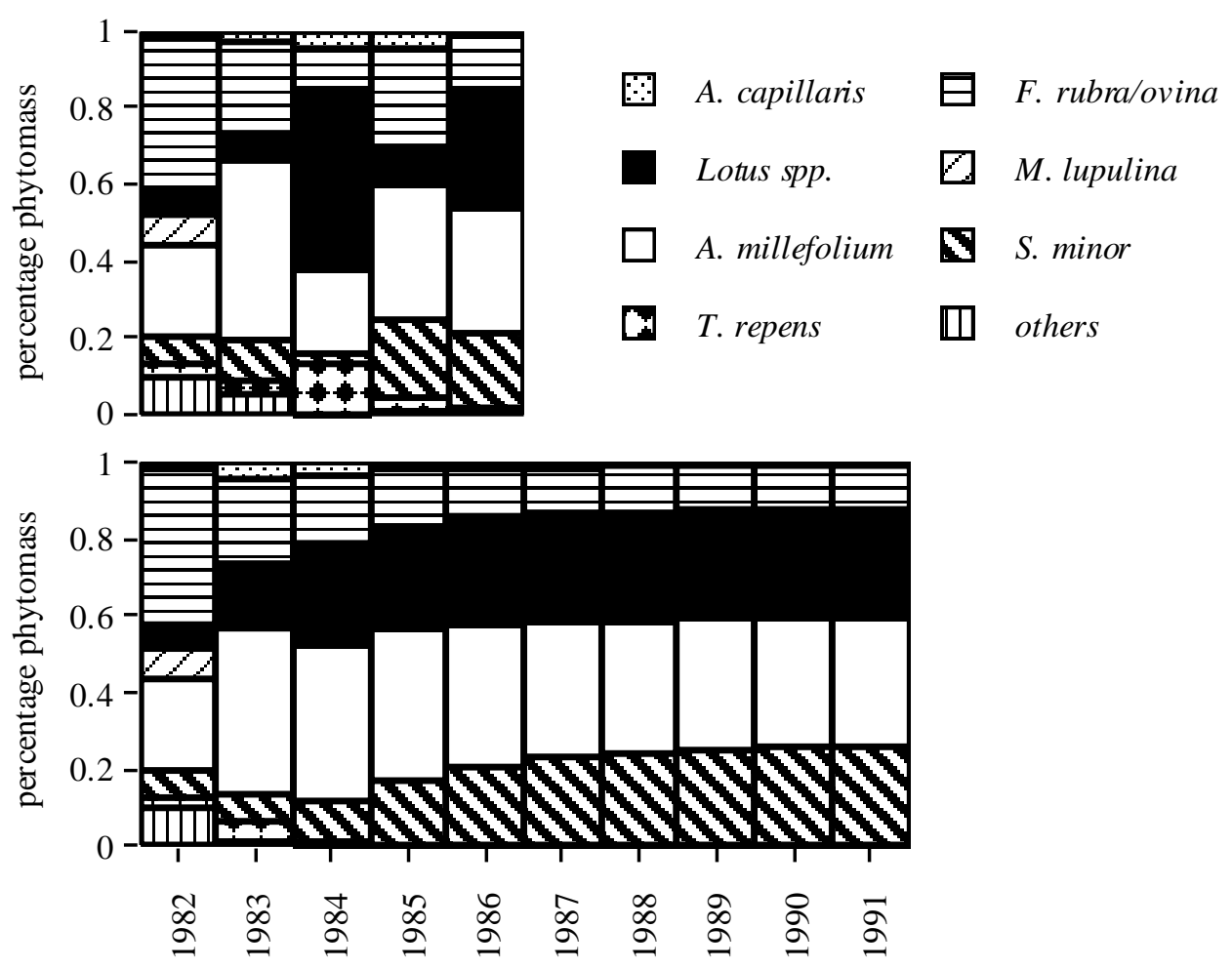

Figure 1

Balzter, H. 


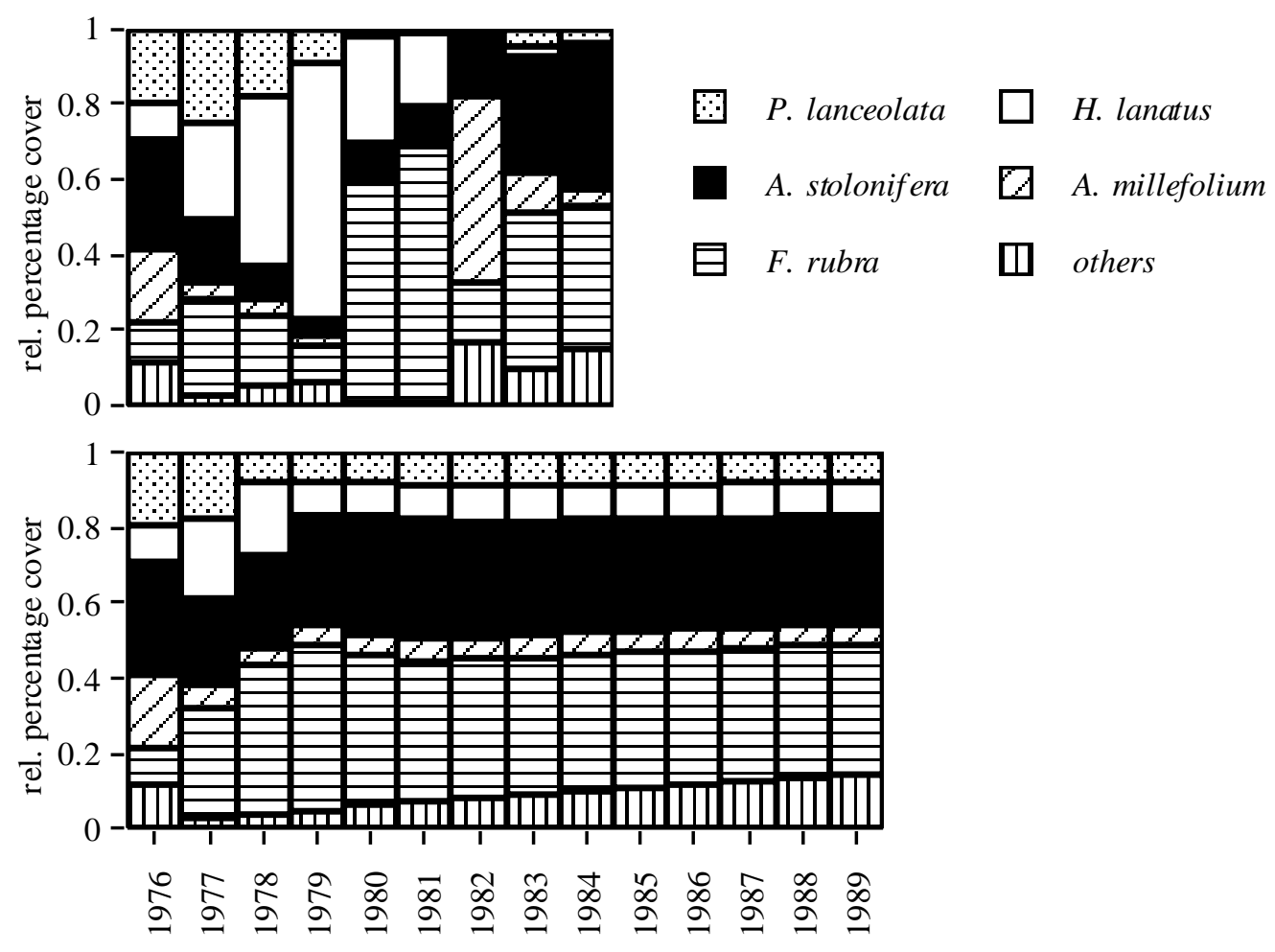

Figure 2

Balzter, H. 

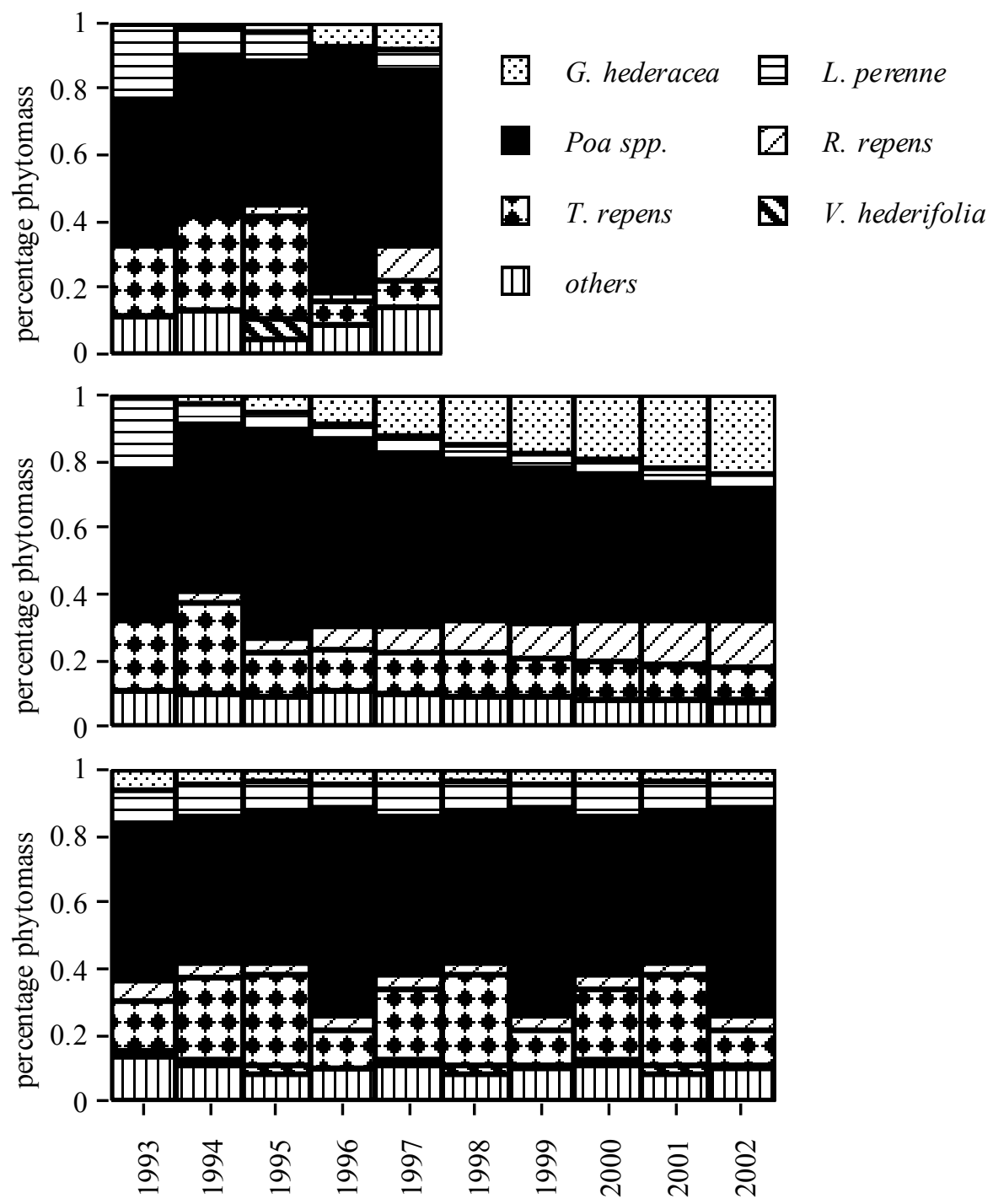

Figure 3

Balzter, H. 

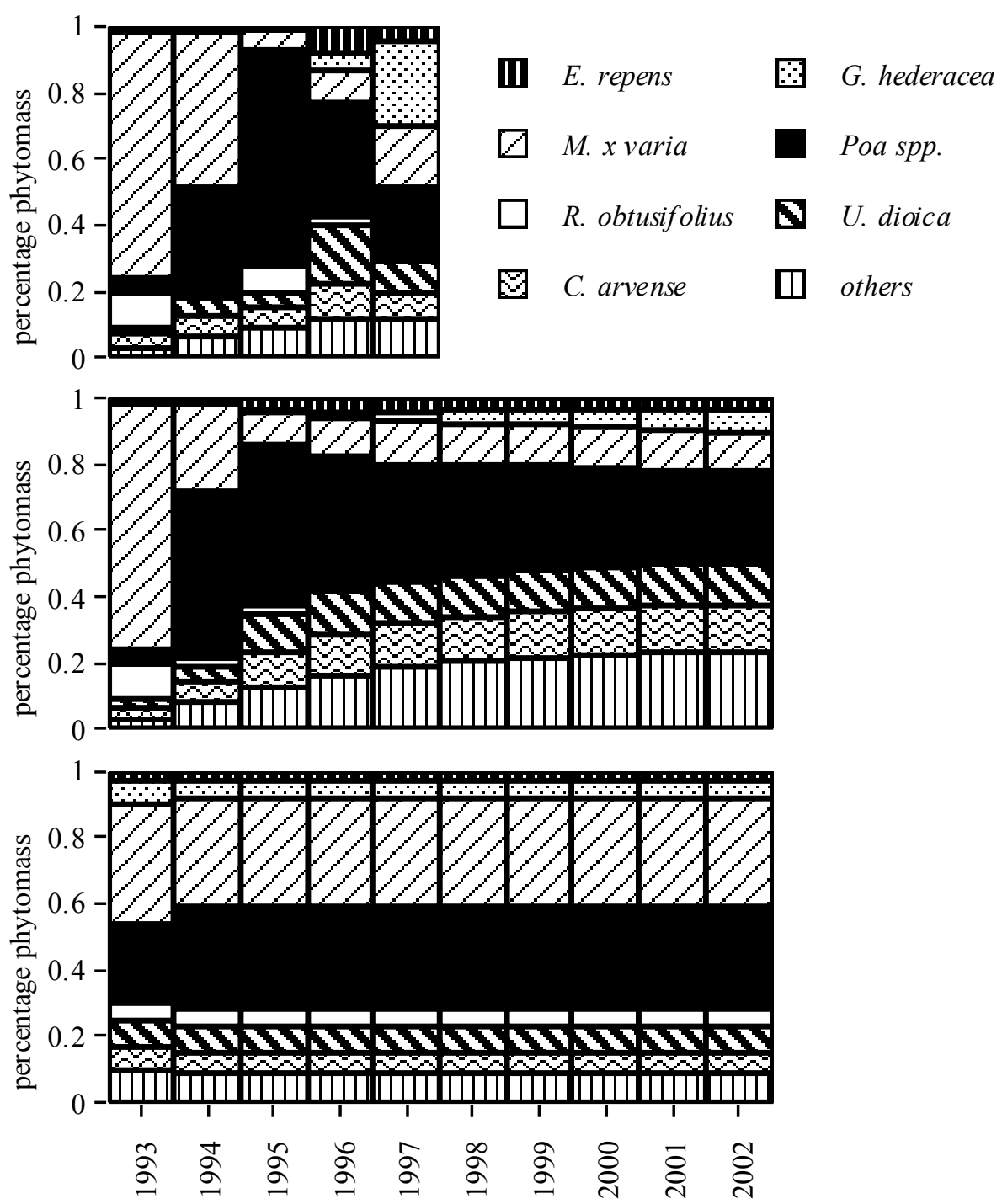

Figure 4

Balzter, H. 

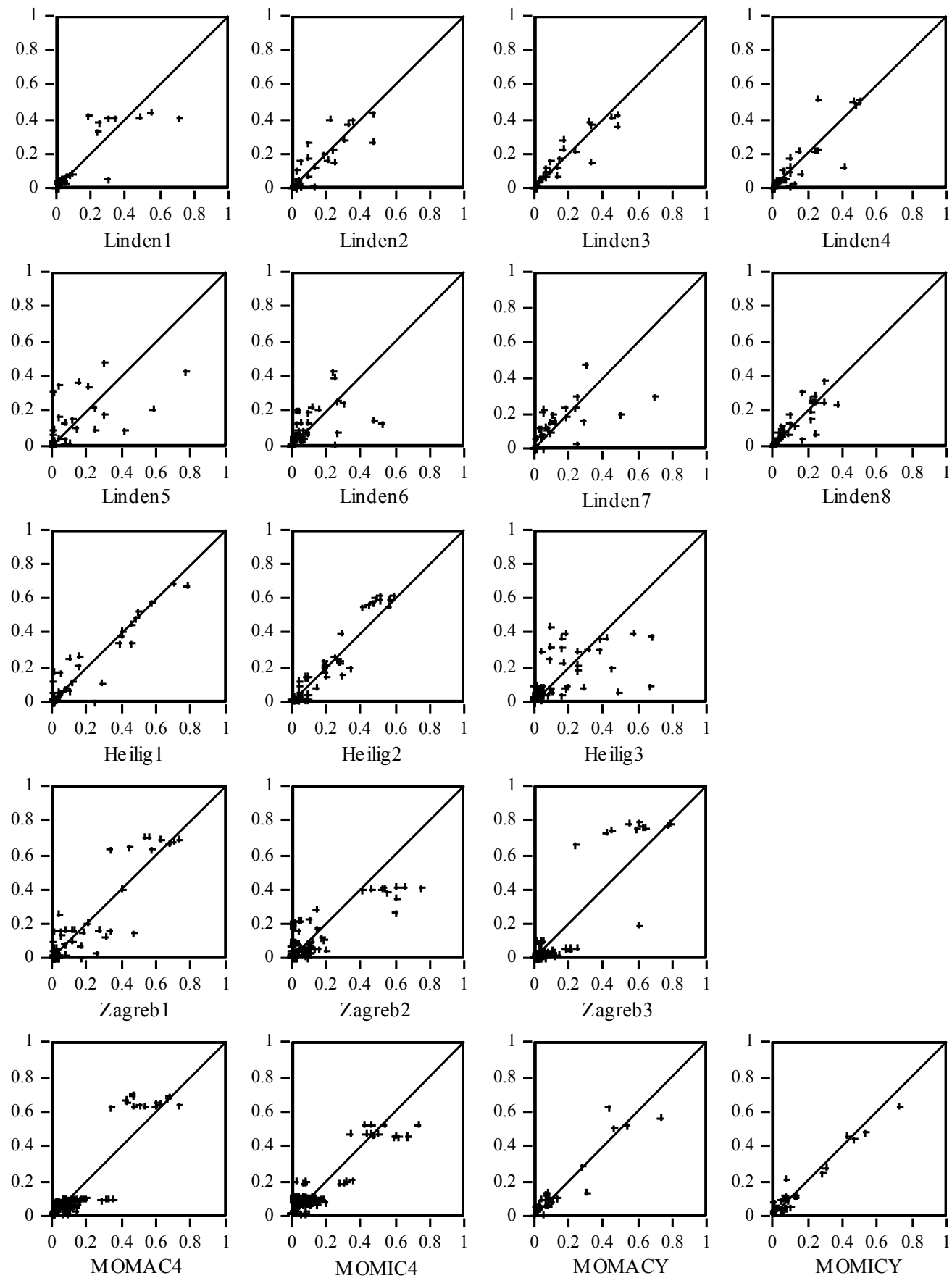

MOMAC4
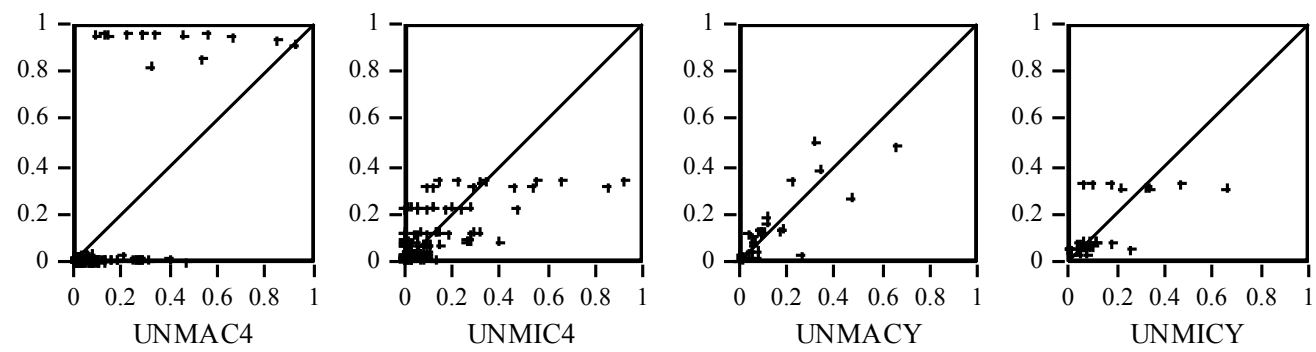

Figure 5

Balzter, $\mathrm{H}$. 


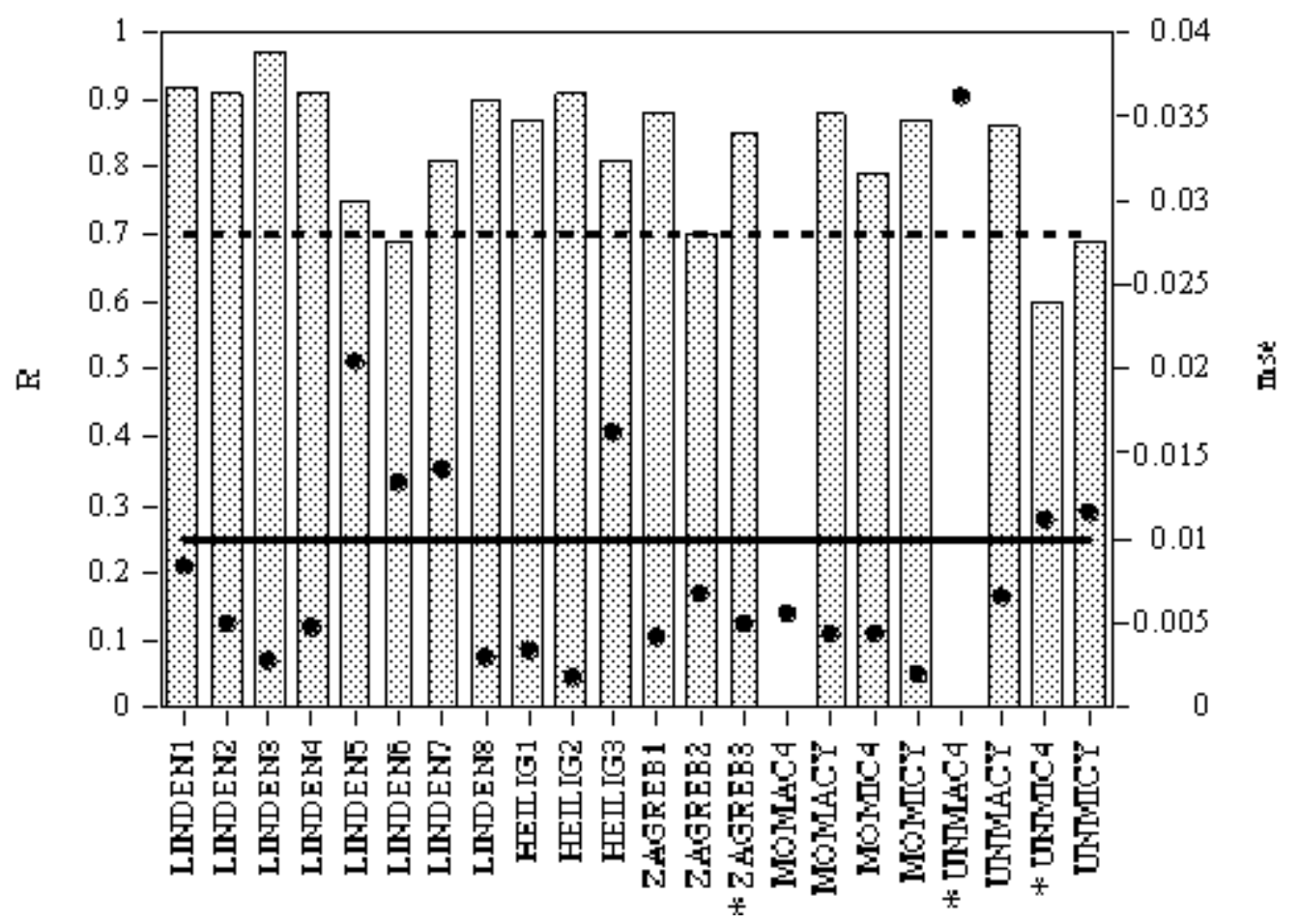

Figure 6

Balzter, H. 


\section{$\underline{\text { Figure captions }}$}

Figure 1: Changes in percentage phytomass of the plant species in plot LINDEN2. Observations (top) and predictions based on 1982 (bottom). The species Agrostis capillaris, Festuca rubra/ovina, Medicago lupulina (black medick), Achillea millefolium, Trifolium repens, Sanguisorba minor and Lotus spp. are presented separately. Species that never exceeded 5\% phytomass are aggregated to the state 'others'.

Figure 2: Changes in relative percentage cover of the plant species in plot HEILIG3. Observations (top) and predictions based on 1976 (bottom). The species Plantago lanceolata (ribwort), Holcus lanatus, Agrostis capillaris, Achillea millefolium and Festuca rubra are presented separately. Trifolium repens, Dactylis glomerata, Rumex acetosa, Cirsium arvense and Stellaria graminea are modelled as separate states but aggregated to the category 'others' for graphical presentation.

Figure 3: Changes in percentage phytomass of the plant species in the mown part of the meadow in Giessen. Observations (top), predictions based on June 1993 for MOMACY

(centre) and for MOMICY (bottom). The species Glechoma hederacea, Lolium perenne, Poa spp., Ranunculus repens, Trifolium repens and Veronica hederifolia (ivy speedwell) are presented separately. Species that never exceeded 5\% phytomass are aggregated to the state 'others'. Predictions for MOMICY are obtained from predicted cluster frequencies. 
Figure 4: Changes in percentage phytomass of the plant species in the unmown part of the meadow in Giessen. Observations (top), predictions based on June 1993 for UNMACY (centre) and for UNMICY (bottom). The species Glechoma hederacea, Medicago x varia, Poa spp., Rumex obtusifolius (broad-leaved dock), Urtica dioica, Cirsium arvense and Elymus repens (couch-grass) are presented separately. Species that never exceeded 5\% phytomass are aggregated to the state 'others'. Predictions for UNMICY are obtained from predicted cluster frequencies.

Figure 5: Scatterplots of predicted vs. observed values for all modelled vegetation datasets.

Figure 6: Comparison of the goodness of fit of all Markov models assessed with Spearman's R and the mean square error (mse). '*' indicates models with significant deviation from the observations (Wilcoxon test, $P<0.05$ ). Due to inhomogeneity $\mathrm{R}$ is not calculated for MOMAC4 and UNMAC4. 